\title{
Redes empresariais como estratégia para o aumento da competitividade em APLs
}

\section{Corporate networks as a strategy for increased competitiveness in APLs}

Jaqueline Guimarães Santos ${ }^{[a]}$, Minelle Éneas da Silva ${ }^{[b]}$, Gesinaldo Ataíde Cândido ${ }^{[c]}$

[a] Mestranda em Administração pela Universidade Federal de Pernambuco (UFPE), Recife, PE - Brasil, email: jsantos.adm@gmail.com

[b] Mestrando em Administração pela Universidade Federal de Pernambuco (UFPE), Recife, PE - Brasil, email: minele.adm@gmail.com.

[c] Doutor em Engenharia de Produção pela Universidade Federal de Santa Catarina (UFSC), professor do Programa de PósGraduação em Recursos Naturais da Universidade Federal de Campina Grande (UFCG), Campina Grande, PB - Brasil, email: gacandido@uol.com.br.

\section{Resumo}

A atual dinâmica organizacional implica na necessidade de novas formas de atuação organizacional baseadas na aplicação de princípios de redes sociais, envolvendo práticas associadas e cooperativas para viabilizar estratégias organizacionais distintas. Uma destas novas formas tem ocorrido através dos arranjos produtivos locais (APLs), a qual contribui para o aumento da competitividade. Neste sentido, o objetivo deste estudo é identificar o grau de competitividade no arranjo produtivo local de madeira e móveis localizado na cidade de Campina Grande, PB. A metodologia utilizada fundamenta-se no modelo de competitividade sistêmica de Coutinho e Ferraz (1994), que analisa um conjunto de fatores para atividades econômicas específicas. 0 estudo é caracterizado como exploratório e descritivo e conduzido sob a forma de um estudo de caso. Os dados foram coletados através de entrevistas realizadas com empresários do setor e complementadas com a análise de dados secundários e da observação não participante. Os resultados obtidos apontam que a competitividade do APL em questão se apresenta desfavorável na maioria dos indicadores em análise, com maior incidência naqueles relacionados à cooperação, o que indica a necessidade de fortalecer os mecanismos de adoção das práticas de redes sociais.

Palavras-chave: Redes interempresariais. Competitividade. Arranjo produtivo local.

\section{Abstract}

The current organizational dynamics implies the need for new forms of work organization based on the application of principles of social networks, involving cooperatives and associated practices to enable different organizational strategies. One of these has occurred through new forms of Local Productive Arrangements (APLs), which contributes to increased competitiveness. In this sense, the objective of this study is to identify the degree of competitiveness 
in the APL of wood and furniture located in the Campina Grande, PB. The methodology is based on the model of systemic competitiveness of Coutinho and Ferraz (1994), which analyzes a set of factors to specific economic activities. The study is characterized as exploratory and descriptive conducted in the form of a case study. Data were collected through interviews with business sector and supplemented by secondary data analysis and non participant observation. These results indicate that a competitiveness of APL in question presents itself in the most unfavorable indicators under consideration, focusing on those related to cooperation, which indicates the need to strengthen mechanisms for adopting social networking practices.

Keywords: Networks interenterprise. Competitiveness. Local production arrangement.

\section{Introdução}

No panorama do século XXI, os desafios enfrentados pelas empresas indicam que há a necessidade de se realizar práticas cooperativas com o intuito de conquistar forças para alcançar uma maior competitividade. Devido à alta concorrência de um mercado cada vez mais complexo e globalizado, encontrar maneiras de alcançar esta finalidade é um fator crucial para a sua sobrevivência. Assim sendo, considera-se a realização de associações cooperativas que auxiliem no desenvolvimento de combinações harmônicas entre as empresas, tendo em vista que suas diferentes competências podem gerar um nível de competição, comprometendo a atuação da empresa. Essas cooperações, de modo geral, são denominadas redes interempresariais.

Segundo Cândido e Abreu (2000), o objetivo da interação entre atores e organizações nas redes é uma tentativa de ampliar o número de parceiros, a fim de viabilizar interesses e projetos comuns. Com isso, essas parcerias podem contribuir para que haja a competitividade em um determinado setor. Neste contexto, para que seja escolhida a melhor alternativa dentre as formas de relacionamento, é interessante que as empresas envolvidas façam parte de aglomerações produtivas, as quais apresentem características físicas semelhantes e que participem do mesmo ramo de atividade.

Nesse sentido, para esse estudo utiliza-se o conceito de Arranjo Produtivo Local (APL), já que se assemelha melhor no perfil das empresas estudadas, como facilitador ao desenvolvimento de uma dada localidade. Para tanto, de acordo com o mapeamento realizado pelo IPEA (2007), identificou-se que no Estado da Paraíba existem vinte arranjos produtivos distribuídos por várias regiões. Especificamente na cidade de Campina Grande, foram identificados sete APLs, dentre os quais se selecionou o de madeira e móveis, um setor tradicional e com características únicas.

Assim sendo, o objetivo desse estudo é identificar o grau de competitividade do Arranjo Produtivo Local de madeira e móveis localizado na cidade de Campina Grande, PB. A metodologia utilizada fundamenta-se no modelo de competitividade sistêmica de Coutinho e Ferraz (1994), que analisa três fatores determinantes, a saber: fatores sistêmicos, estruturais e empresariais. $\mathrm{O}$ estudo é caracterizado como um estudo exploratório e descritivo, sob a forma de um estudo de caso no APL de madeira e móveis. Os atores sociais pesquisados constituíram-se dos empresários do setor, envolvendo a realização de entrevistas a partir de um roteiro semiestruturado.

Como forma de reconhecer as características competitivas no APL em análise, esse artigo está dividido em cinco seções. Além da presente introdução, a segunda seção trabalha os conceitos referentes a redes interempresariais, arranjo produtivo local, competitividade. A seção três apresenta os aspectos metodológicos para a realização da pesquisa, bem como apresenta algumas características do setor de madeira e móveis. Em seguida, verifica-se a análise e apresentação dos resultados e, por fim, a quinta seção trata das considerações finais.

\section{Referencial teórico}

No presente capítulo encontram-se referenciados autores clássicos e contemporâneos que direcionam seus trabalhos para os temas em análise, em especial para Redes interempresariais e aglomerados produtivos, Arranjo Produtivo Local e, por fim, Competitividade, com o objetivo maior de obter um efetivo embasamento teórico, além de disponibilizar para o leitor informações relevantes para um 
adequado entendimento do que estará sendo discutido ao longo do desenvolvimento deste trabalho.

Nesse sentido, o arcabouço teórico é resultante da exposição das diversas visões, ideias e posicionamentos dos autores na área, na medida em que permite visualizar as compatibilidades e confrontos existentes entre as mesmas, fornecendo os devidos fundamentos para a pesquisa e, sobretudo, suporte para realização da mesma.

\section{Redes interempresariais e aglomerados produtivos}

Na literatura consegue-se identificar diversos tipos de formas de relacionamentos, que auxiliam no crescimento da empresa e aumentam o grau competitivo, corroborando para com o objetivo de todas as organizações, qual seja: buscar reconhecimento dentro de área de atuação, bem como ampliar suas atividades conquistando maior competitividade. Neste contexto, para questão deste estudo serão abordados, a priori, os conceitos referentes a alianças estratégicas e parcerias, que se apresentam como possíveis formas de cooperação utilizadas no setor em estudo.

Identifica-se, portanto, a necessidade de maior entendimento do que venham a ser esses conceitos. Em uma primeira averiguação, observa-se que as alianças estratégicas, segundo Noleto (2000), são associações que visam melhorar as posições e objetivos das organizações, envolvendo a cooperação de duas ou mais entidades, na qual todas as partes se fortalecem mutuamente.

Ponto que reafirma, como uma fonte estratégica, o alto grau de interação entre as empresas, visto que todas almejam, ao realizar essa forma de relacionamento, possuir um destaque no mercado. Outro fato que se pode observar é o compartilhamento de habilidades e informações, assim como dos muitos riscos que existem nas transações, para que se consiga atingir um fim comum.

Esta é exatamente uma das características das parcerias, na qual os envolvidos em determinado setor econômico reconhecem a necessidade de realizar algum tipo de associação, somando suas competências na busca por objetivos comuns para as partes envolvidas (NOLETO, 2000). Desta forma, esses aspectos podem ser confirmados de acordo com Cândido e Abreu (2000), pois as "organizações do mesmo ramo industrial frequentemente se juntam sob o mesmo 'guarda-chuva' de associações comerciais e profissionais, cooperando no sentido de interesses compartilhados".

De fato, se as empresas conseguem realizar cooperações como condicionantes estratégicos, identifica-se uma grande capacidade de percepção de mercado, ou mesmo uma indução do ambiente para que aspectos semelhantes favoreçam as práticas de uma dada empresa. Ou seja, se torna um ponto facilitador do desenvolvimento de alianças e parcerias com o intuito de melhorar o desempenho dos atores envolvidos, bem como da economia no qual o arranjo está inserido. A atuação destes aglomerados facilita tanto o desempenho da empresa perante seus concorrentes, como auxiliam na manutenção destas empresas no mercado. 0 que pode favorecer a competitividade das localidades onde os arranjos produtivos atuam.

\section{Arranjo produtivo local (APL)}

Ao conciliar as características empresariais com associações cooperativas em um setor econômico específico, são perceptíveis as relações existentes deste relacionamento com as aglomerações produtivas. Esse conceito foi criado para intensificar o desenvolvimento local, dando ênfase à formação de aglomerações de micro, pequenas e médias empresas, localizadas numa concentração geográfica e focadas numa atividade principal.

Criados com o intuito de potencializar a economia de uma localidade, os chamados arranjos produtivos locais (APLs) apresentam inegavelmente as características necessárias a esse desenvolvimento. Portanto, esses podem ser caracterizados como aglomerações territoriais de agentes econômicos, políticos e sociais com foco em uma atividade empresarial específica. Geralmente envolvem a participação de muitas empresas que buscam o desenvolvimento dentro do setor (CASSIOLATO; LASTRES, 2004).

Assim sendo, pode-se entender que a existência de aglomerados produtivos assume um papel de facilitador ao desenvolvimento de um dado local. Todavia, é necessário destacar que, além de participar de um aglomerado produtivo, as organizações devem buscar outras maneiras de amplificar sua capacidade competitiva. Havendo, assim, a necessidade de criação de redes interempresariais, já que apresentam um fator interessante de cooperações ou parcerias para o alcance de objetivos em comum. 
Quando uma empresa faz parte de arranjo produtivo, a tendência inerente a este fato é que o grau competitivo desta localidade aumente, pois a ideia primordial de um APL é a integração entre as empresas que fazem parte do mesmo, formando as redes interempresariais, associações, entre outras.

\section{Competitividade}

A participação das empresas em um arranjo produtivo amplia a possibilidade de modificações no grau competitivo dentro do ambiente que circunda as organizações. Com isso, utilizar modelos que intensifiquem a competitividade é imprescindível, ao mesmo tempo em que a estratégia seja integrada às diferentes formas de cooperações. Apesar de vários estudos acerca da competitividade, não se tem um consenso quanto a sua definição, mas pode-se elencar duas famílias de conceitos para a mesma. Em uma primeira instância a competitividade pode ser vista como desempenho.

Para Ferraz, Kupfer e Haguenauer (1997), a competitividade é expressa, de alguma forma, pela participação no mercado (market-share) alcançada por uma firma ou conjunto de firmas no comércio internacional total da mercadoria. Apareceria como seu indicador mais imediato, mais especificamente quando se estuda a competitividade internacional. Na segunda família, ainda segundo os autores, a competitividade é vista como eficiência, na qual tenta-se traduzi-la através da relação insumo-produto, ou seja, a empresa obter máximo rendimento na conversão de insumo e produto.

Para efeito de análise, existem alguns conceitos em torno deste tema indicando sempre que, mesmo sem a intenção de se tornar competitivo, todas as empresas, por pertencerem à dinâmica do mercado, têm que, de alguma forma, possuir as competências necessárias para a sobrevivência, obtendo assim um perfil competitivo. Segundo Ferraz, Kupfer e Haguenauer (1997), a competitividade pode ser definida como "a capacidade da empresa em formular e implementar estratégias concorrenciais, que lhe permitam ampliar ou conservar, de forma duradoura, uma posição sustentável no mercado".

Assim, para conseguir mensurar o grau competitivo, neste estudo, se faz necessário a utilização de um modelo de competitividade. Para tanto, foi escolhido o modelo de Coutinho e Ferraz (1994), representado pelo Quadro 1.
Para motivar a competitividade, observa-se a necessidade de se analisar três fatores, a saber: fatores sistêmicos, fatores estruturais e fatores empresariais. Percebe-se ainda que, para determiná-los, é necessário utilizar aspectos internos à empresa, referente às externalidades e ao ambiente no qual a empresa está inserida.

Os fatores sistêmicos são aqueles que sofrem influências do ambiente, porém não possuem condições de intervir no mesmo. Os fatores estruturais são aqueles nos quais a empresa tem capacidade limitada de intervenção, pela mediação do processo de concorrência, estando por isso parcialmente sob sua área de influência. Já os fatores empresariais são aqueles pelos quais as empresas detêm todo o poder de decisão e que podem ser controlados, são as variáveis de poder decisório, tendo quatro áreas de competências.

Neste contexto, conciliar os fatores determinantes para a competitividade na intenção de um maior desenvolvimento local se torna interessante, uma vez que envolve aspectos relevantes à existência de cooperações e, consequentemente, de redes interempresariais. Para que este fato seja efetivado, a participação em um Arranjo Produtivo Local se torna um aspecto mais vantajoso, já que facilita o relacionamento entre os atores envolvidos e considera esta a melhor alternativa para as empresas. Assim sendo, a metodologia utilizada envolve os constructos supracitados.

\section{Procedimentos metodológicos}

Com base na análise da competitividade do APL madeira e móveis em Campina Grande, o artigo examina a dinâmica da competitividade entre as empresas que integram esse grupo, situadas na cidade de Campina Grande, PB, e cadastradas na Federação das Indústrias do Estado da Paraíba (FIEP).

De acordo com o relatório da FIEP (2006), na cidade são encontradas 68 empresas que atuam nesta atividade produtiva. Para questão deste estudo, excetuaram-se as 7 empresas que fabricam colchões (móveis do mobiliário), 4 empresas que trabalham com a fabricação de produtos diversos, bem como 3 que fabricam móveis do mobiliário e que não atuam mais no APL. Isso resulta na presença de 54 empresas.

0 estudo foi caracterizado quanto à natureza como sendo aplicado, quanto ao objetivo é descritivo, 
Quadro 1 - Fatores do modelo sistêmico de Coutinho e Ferraz (1994)

\begin{tabular}{|c|c|c|c|}
\hline AUTORES & $\begin{array}{c}\text { SISTÊMICOS } \\
\text { Relativos ao ambiente concorrencial }\end{array}$ & $\begin{array}{c}\text { ESTRUTURAIS } \\
\text { Relativos ao mercado }\end{array}$ & $\begin{array}{c}\text { INTERNOS } \\
\text { Relativos à empresa }\end{array}$ \\
\hline $\begin{array}{l}\text { Coutinho e } \\
\text { Ferraz (1994) }\end{array}$ & $\begin{array}{l}\text { - Macroeconômicos: taxa de câmbio, } \\
\text { carga tributária, taxa de crescimento } \\
\text { do PIB, oferta de crédito e taxa de } \\
\text { juros, política salarial e outros; } \\
\text { - Político-institucional: política tribu- } \\
\text { tária, tarifária, tecnológica, poder de } \\
\text { compra do governo; } \\
\text { - Legais e regulatórios: proteção à } \\
\text { propriedade industrial, preservação } \\
\text { ambiental, defesa da concorrência, } \\
\text { proteção do consumidor, regulação } \\
\text { do capital estrangeiro; } \\
\text { - Infraestrutura e condições sociais; } \\
\text { - Internacionais: tendência do comér- } \\
\text { cio, fluxo de capital e acordos. }\end{array}$ & $\begin{array}{l}\text { - Mercado: tamanho e dinamis- } \\
\text { mo, grau de sofisticação e acesso } \\
\text { a mercados internacionais; } \\
\text { - Regime de incentivos e regu- } \\
\text { lação da concorrência: aparato } \\
\text { legal, política fiscal e financeira, } \\
\text { política comercial e papel do } \\
\text { Estado; } \\
\text { - Configuração da indústria: } \\
\text { desempenho e capacitação, es- } \\
\text { trutura patrimonial e produtiva, } \\
\text { articulações na cadeia. }\end{array}$ & $\begin{array}{l}\text { - Inovação } \\
\text { - Recursos humanos } \\
\text { - Gestão }\end{array}$ \\
\hline
\end{tabular}

Fonte: MACÊDO; SILVA; BARROS, 2010.

na medida em que objetiva descrever as características de determinado fenômeno. Quanto à tipologia optou-se por um estudo de caso, visto que este tipo, segundo Santos (1999, p. 27), caracteriza-se pela seleção de "objeto de pesquisa restrito, com o objetivo de aprofundar-lhe os aspectos característicos".

Em se tratando da abordagem, a pesquisa pode ser considerada como de ordem qualitativa, tendo como técnicas de coletas de dados entrevistas semiestruturadas e aplicação de questionário contemplado por 100 questões, informações estas coletadas junto aos dirigentes de cada empresa. 0 período de coleta de dados teve seu curso entre 10/02/09 e 30/03/09, ao realizar-se uma pesquisa de campo, com amostra do tipo não probabilística por acessibilidade, e representa $25,00 \%$ do universo populacional existente neste setor.

A metodologia utilizada para a pesquisa foi a de Coutinho e Ferraz (1994), a qual analisa três fatores: sistêmicos, estruturais e empresariais. Desta forma, as informações captadas pelo conjunto de variáveis destes fatores foram analisadas a partir dos parâmetros de análise para cada variável, conforme observa-se no Quadro 2 abaixo, as quais proporcionaram ampliar a observação da competitividade sob um entendimento holístico do APL.

Para a realização da análise da competitividade do APL de madeira e móveis campinense, foram criados parâmetros de análise com o objetivo de classificar se cada variável contribui favoravelmente ou desfavoravelmente à competitividade do arranjo, na busca de um melhor entendimento do mesmo nas dimensões macro, meso e micro, sendo estes representados, respectivamente, pelos fatores sistêmico, estrutural e empresarial que compõem o modelo de Coutinho e Ferraz (1994). É importante destacar que os valores apresentados em porcantagem para cada dimensão é calculado a partir de uma média simples entre as variáveis que foram consideradas como favorável ou não à competitividade, esta sendo uma maneira de representação da avaliação feita qualitativamente, bem como possibilitar o entendimento do impacto que cada fator representa na competitividade global do arranjo.

\section{Caracterização do setor de madeira e móveis}

Há uma evolução crescente do setor de madeira e móveis nos últimos anos, o qual sofreu grandes transformações em todo o mundo com consequentes ganhos de produtividade, a partir da introdução de equipamentos automatizados e da utilização de novas técnicas de gestão. As mudanças incluem o uso crescente de novas fontes de matérias-primas, já que por questões ambientais, madeiras nobres 
se encontram hoje com aplicação restrita. A Itália é o maior exportador mundial de móveis. Seu sucesso deve-se ao design e à qualidade de seus produtos, além dos preços competitivos, mas o país é muito dependente de matéria-prima importada. Já os Estados Unidos, que também são grandes exportadores, são os maiores importadores de móveis do mundo.

O Brasil ocupa a $18^{\text {a }}$ posição entre os maiores exportadores de madeira e móveis, sendo os principais compradores os Estados Unidos, a Argentina e a França. Contudo, nos últimos dez anos, houve um aumento considerável de sua participação no total de exportações. A indústria brasileira de móveis está localizada, basicamente, no Sul e Sudeste do País: Rio Grande do Sul, Santa Catarina, Paraná, São Paulo, Minas Gerais e Rio de Janeiro concentram 75\% das empresas, sendo Santa Catarina o maior exportador, responsável por aproximadamente metade das vendas brasileiras de móveis para o exterior. Segundo a ABIMÓVEL (2006), o APL de madeira e móveis apresenta 16.104 em número de empresas do setor, gerando 206.352 empregos em todo o país, sendo este considerado um setor que oferece poucas oportunidades de empregos.

A Paraíba não apresenta, segundo a ABIMÓVEL, valores referentes à exportação. 0 que pode refletir as características de seus dois arranjos produtivos de madeira e móveis paraibano, que estão focados principalmente no mercado local. O APL de madeira e móveis campinense sofre bastante influência das características nacional e estadual, visto que representa um aglomerado de empresas com semelhanças particulares e consegue, desta maneira, envolver os conhecimentos necessários para um maior desenvolvimento local.

\section{Apresentação e análise dos resultados}

A cidade de Campina Grande apresenta, de acordo com o estudo do IPEA (2007), a maior quantidade de aglomerados produtivos do estado da Paraíba, estando todos estes classificados como vetores avançados para a economia estadual. 0 aglomerado produtivo em estudo pode ser considerado como tradicional e densamente homogêneo, o que condiciona a uma melhor análise do setor. O APL de madeira e móveis está caracterizado em dois grandes segmentos: madeira e móveis. 0 primeiro compreende as atividades de desdobramento de madeira e fabricação de produtos de madeira, cortiça e trançado, exceto móveis; e o segundo segmento trabalha com fabricação de móveis do mobiliário (móveis em madeira, tubulares, estofados e colchões) e fabricação de produtos diversos.

Percebe-se que existem, em sua maioria, empresas de pequeno porte, com capital nacional e que utilizam apenas capital próprio em suas atividades. A característica de tradicional pode ser confirmada, pois as empresas nasceram antes dos anos 90, tendo quase todos os proprietários nascido na cidade.

Quadro 2 - Parâmetros de análise criados para a identificação da competitividade

(continua)

\begin{tabular}{lll}
\hline Dimensão & \multicolumn{1}{c}{$\begin{array}{c}\text { Determinantes da competitividade - fatores sistêmicos } \\
\text { Parâmetros }\end{array}$} \\
\hline Determinantes estruturais & $\begin{array}{l}\text { Características do setor de madeira e } \\
\text { móveis }\end{array}$ & $\begin{array}{l}\text { Se houver reconhecimento do setor pelos atores en- } \\
\text { volvidos na economia, maior a probabilidade de haver } \\
\text { competitividade. }\end{array}$ \\
\hline $\begin{array}{l}\text { Determinantes internacio- } \\
\text { nais }\end{array}$ & Oscilação nas demandas de mercado & $\begin{array}{l}\text { Quanto maior a estabilidade da demanda, maior a } \\
\text { chance de se tornar competitivo. }\end{array}$ \\
& $\begin{array}{l}\text { Formas de relacionamento entre as } \\
\text { empresas }\end{array}$ & $\begin{array}{l}\text { Quanto mais flexíveis as estruturas, maior a chance de } \\
\text { ser competitivo. }\end{array}$ \\
\hline $\begin{array}{l}\text { Quanto melhor for o relacionamento entre as empresas, } \\
\text { meterminantes político- }\end{array}$ & $\begin{array}{l}\text { Inconstância de políticas de apoio e/ou competitividade. } \\
\text { falta de apoio governamental }\end{array}$ & $\begin{array}{l}\text { Quanto menor a instabilidade das políticas, incentivos e } \\
\text { apoio institucional, melhor para a competitividade. }\end{array}$ \\
\hline $\begin{array}{l}\text { Determinantes macro- } \\
\text { econômicos }\end{array}$ & Carga tributária e encargos sociais & $\begin{array}{l}\text { Quanto menor a carga tributária e os encargos sociais, } \\
\text { maior a competitividade. }\end{array}$ \\
\hline
\end{tabular}


Quadro 2 - Parâmetros de análise criados para a identificação da competitividade

\begin{tabular}{|c|c|c|}
\hline \multicolumn{3}{|c|}{ Determinantes da competitividade - fatores estruturais } \\
\hline Dimensão & Variáveis & Parâmetros \\
\hline \multirow{10}{*}{ Caracterização do APL } & Origem do APL & $\begin{array}{l}\text { Quanto melhores os fatores para a criação de um ar- } \\
\text { ranjo, melhor para a competitividade. }\end{array}$ \\
\hline & Tempo de atuação & $\begin{array}{l}\text { Quanto maior o tempo de atuação, mais estável o APL } \\
\text { e, portanto, maior a favorabilidade. }\end{array}$ \\
\hline & Origem do capital & $\begin{array}{l}\text { Quanto maior a quantidade de capital nacional, o } \\
\text { alcance de competividade se torna mais favorável. }\end{array}$ \\
\hline & Origem do proprietário & $\begin{array}{l}\text { Caso ele seja natural do município, propensamente } \\
\text { torna-se mais favorável o desenvolvimento de competi- } \\
\text { tividade. }\end{array}$ \\
\hline & Funcionários próprios/terceirizados & $\begin{array}{l}\text { Quanto maior a quantidade de funcionários próprios, } \\
\text { melhor o desempenho da empresa, pela exatidão e } \\
\text { comprometimento. }\end{array}$ \\
\hline & Capacidade produtiva & $\begin{array}{l}\text { Quanto maior a capacidade produtiva da empresa, } \\
\text { maior se tornará a produção e, por conseguinte, a } \\
\text { competitividade. }\end{array}$ \\
\hline & Linha de produtos & $\begin{array}{l}\text { Quanto maior a quantidade de produtos, maior a } \\
\text { competitividade. }\end{array}$ \\
\hline & Processo produtivo & $\begin{array}{l}\text { Quanto mais etapas da produção a empresa tiver } \\
\text { domínio, mas chance de ser competitivo. }\end{array}$ \\
\hline & Sistemas de produção & $\begin{array}{l}\text { Quanto mais sistemas forem adotados pela empresa, } \\
\text { maior a chance de competitividade. }\end{array}$ \\
\hline & Formas de produção & $\begin{array}{l}\text { Se a forma de produção adotada facilitar as atividades da } \\
\text { organização, maior a probabilidade de competitividade. }\end{array}$ \\
\hline \multirow{7}{*}{ Caracterização do APL } & Desempenho e capacitação & $\begin{array}{l}\text { Quanto maior a participação da empresa na economia, } \\
\text { bem como a capacitação dos empregados, melhor a } \\
\text { competitividade. }\end{array}$ \\
\hline & Empresas correlatas e de apoio & $\begin{array}{l}\text { Quanto maior a proximidade de empresas distribuido- } \\
\text { ras para o APL, maior a chance de ser competitivo. }\end{array}$ \\
\hline & Empresas de comercialização & $\begin{array}{l}\text { Quanto melhor a quantidade de empresas que vendem } \\
\text { os seus produtos, maior a competitividade. }\end{array}$ \\
\hline & Instituição de apoio & $\begin{array}{l}\text { Quanto mais instituições envolvidas e agindo de forma } \\
\text { ativa, melhor para a competitividade. }\end{array}$ \\
\hline & Terceirização & $\begin{array}{l}\text { Quanto mais atividades a empresa obtiver controle, } \\
\text { maior a propensão à competitividade. }\end{array}$ \\
\hline & $\begin{array}{l}\text { Articulação na cadeia produtiva por } \\
\text { meio da cooperação }\end{array}$ & $\begin{array}{l}\text { Se houver cooperação entre as empresas, melhor para } \\
\text { o desenvolvimento do APL e, por conseguinte, maior a } \\
\text { chance de competitividade. }\end{array}$ \\
\hline & $\begin{array}{l}\text { Articulação na cadeira produtiva por } \\
\text { meio do fluxo de informações. }\end{array}$ & $\begin{array}{l}\text { Quanto melhor o fluxo de informações entre as empre- } \\
\text { sas do APL, maior a probabilidade de competitividade. }\end{array}$ \\
\hline
\end{tabular}


Quadro 2 - Parâmetros de análise criados para a identificação da competitividade

(continua)

\begin{tabular}{|c|c|c|}
\hline \multirow{8}{*}{$\begin{array}{l}\text { Regime de incentivo e } \\
\text { regulação da concorrência }\end{array}$} & Localização & $\begin{array}{l}\text { Quanto mais estratégica a localização, melhor para a } \\
\text { competitividade. }\end{array}$ \\
\hline & Financiamentos & $\begin{array}{l}\text { Quanto maior a disponibilidade e efetiva utilização das } \\
\text { linhas de crédito, maior a possibilidade de ser competi- } \\
\text { tivo. }\end{array}$ \\
\hline & Informalidade & $\begin{array}{l}\text { Quanto menor a quantidade de empresas informais, } \\
\text { maior a chance do arranjo ser competitivo. }\end{array}$ \\
\hline & $\begin{array}{l}\text { Mão de obra qualificada e de treina- } \\
\text { mento }\end{array}$ & $\begin{array}{l}\text { Quanto maior a disponibilidade de mão de obra qualifi- } \\
\text { cada, melhor à competitividade. }\end{array}$ \\
\hline & $\begin{array}{l}\text { Incentivos das instituições de apoio, } \\
\text { sindicatos e governo. }\end{array}$ & $\begin{array}{l}\text { Quanto maiores os incentivos, cursos preparatórios e/ } \\
\text { ou qualquer outro investimento, melhor a competitivi- } \\
\text { dade. }\end{array}$ \\
\hline & $\begin{array}{l}\text { Inexistência de mecanismos de coope- } \\
\text { ração entre pequenas empresas }\end{array}$ & $\begin{array}{l}\text { Se não existir cooperação entre as empresas, melhor a } \\
\text { possibilidade de competitividade. }\end{array}$ \\
\hline & Falta de atualização tecnológica & $\begin{array}{l}\text { Quanto maiores os níveis de atualização tecnológica, } \\
\text { melhor para a competitividade. }\end{array}$ \\
\hline & Políticas para reestruturação do setor & $\begin{array}{l}\text { A existência e efetivação de políticas direcionadas } \\
\text { para a reestruturação do setor ampliam a chance de } \\
\text { competitividade. }\end{array}$ \\
\hline \multirow{4}{*}{ Mercado } & Área de influência & $\begin{array}{l}\text { Quanto mais clientes o APL possuir fora do estudo, } \\
\text { maior influência e participação terá, se tornando mais } \\
\text { competitivo. }\end{array}$ \\
\hline & Concorrência interna & $\begin{array}{l}\text { Quanto mais transparente o nível de concorrência, mais } \\
\text { propício à competitividade. }\end{array}$ \\
\hline & Valorização do produto local & $\begin{array}{l}\text { Quanto maior a quantidade de produtos vendidos } \\
\text { localmente, melhor para a competitividade. }\end{array}$ \\
\hline & Acesso a mercados internacionais & $\begin{array}{l}\text { Se a empresa realizar exportação, maior a divulgação } \\
\text { de seus produtos e a chance de se tornar competitivo. }\end{array}$ \\
\hline \multicolumn{3}{|c|}{ Determinantes da competitividade - fatores empresariais } \\
\hline Dimensão & Variáveis & Parâmetros \\
\hline \multirow{4}{*}{ Gestão competitiva } & Planejamento e gerenciamento & $\begin{array}{l}\text { Quanto maiores os níveis de gerenciamento e plane- } \\
\text { jamento desenvolvidos pela organização, melhor a } \\
\text { propensão para a competitividade. }\end{array}$ \\
\hline & Controle financeiro & $\begin{array}{l}\text { Quanto maior o controle financeiro, maior a competi- } \\
\text { tividade. }\end{array}$ \\
\hline & Estratégia mercadológica & $\begin{array}{l}\text { Quanto melhor a estratégia de marketing, mais fa- } \\
\text { vorável para a competitividade. }\end{array}$ \\
\hline & Práticas gerenciais cooperativas & $\begin{array}{l}\text { Quanto maior a cooperação entre os colaboradores da } \\
\text { organização, há maior propensão para a competitividade. }\end{array}$ \\
\hline
\end{tabular}


Quadro 2 - Parâmetros de análise criados para a identificação da competitividade

(conclusão)

\begin{tabular}{|c|c|c|}
\hline \multirow{5}{*}{ Inovação } & Inovação na gestão & $\begin{array}{l}\text { Práticas inovativas na forma de gestão organizacional } \\
\text { favorecem o desenvolvimento de competitividade. }\end{array}$ \\
\hline & Inovação no processo & \multirow{3}{*}{$\begin{array}{l}\text { Quanto maior a quantidade de inovações, maior a } \\
\text { probabilidade de haver competitividade. }\end{array}$} \\
\hline & Inovação no produto & \\
\hline & Inovações tecnológicas & \\
\hline & Fontes de informação para a inovação & $\begin{array}{l}\text { Quanto mais atualizadas e diversificadas as fontes de } \\
\text { informação para inovação, melhor para a competitivi- } \\
\text { dade. }\end{array}$ \\
\hline \multirow{3}{*}{ Produção } & Atualização do sistema de produção & $\begin{array}{l}\text { Quanto mais atualizado estiver o sistema de produção, } \\
\text { mais favorável será para a competitividade. }\end{array}$ \\
\hline & Desempenho produtivo & $\begin{array}{l}\text { Quanto melhor desenvolvidas as atividades organizacio- } \\
\text { nais, maior a chance de ser competitivo. }\end{array}$ \\
\hline & Métodos de produção & $\begin{array}{l}\text { Quanto mais métodos de produção a empresa dispor, } \\
\text { melhor a competitividade. }\end{array}$ \\
\hline \multirow{4}{*}{ Recursos humanos } & Qualificação & $\begin{array}{l}\text { Quanto mais qualificados os colaboradores, melhor } \\
\text { para o alcance de uma competitividade. }\end{array}$ \\
\hline & Capacitação e treinamento & $\begin{array}{l}\text { Quanto maior a capacitação e treinamento dos colabo- } \\
\text { radores, melhor para a competitividade. }\end{array}$ \\
\hline & Flexibilidade & $\begin{array}{l}\text { Quanto melhor a flexibilidade de interação na empresa, } \\
\text { maior a probabilidade de se alcançar a competitividade. }\end{array}$ \\
\hline & $\begin{array}{l}\text { Comprometimento e estímulo à com- } \\
\text { petitividade }\end{array}$ & $\begin{array}{l}\text { Quanto mais comprometidos os colaboradores, melhor } \\
\text { para a competitividade. }\end{array}$ \\
\hline
\end{tabular}

Fonte: Dados da pesquisa.

O ambiente de negócios é bastante complexo e, desta forma, consegue-se entender as características dos chamados fatores sistêmicos (Quadro 3) em relação a todos os aspectos analisados aos indicadores envolvidos a este fator.

Este resultado mostra que a maioria dos indicadores deste determinante é desfavorável para a competitividade, fato que pode ser identificado pela falta de cooperação entre os atores envolvidos, como também das variações na economia e do cenário político. Outro ponto que influencia diretamente a falta de competitividade, e que foi intensamente enfatizado pela maioria dos empresários na pesquisa, é a alta carga tributária existente na localidade, visto que interfere fortemente no repasse de preço para o mercado, já que aumenta os custos do produto.

Uma das principais características deste APL são os aspectos favoráveis à localidade, que dizem respeito à qualidade de vida, à proximidade e dimensão dos consumidores, além de outras variáveis estudadas. Quando se refere ao processo produtivo, verifica-se que é alto o nível de independência, já que as empresas, em sua maioria, conseguem realizar todas as etapas de desenvolvimento e produção do produto. Apesar de produzirem produtos muito semelhantes, os participantes do APL conseguem atender todas as necessidades dos clientes, já que a margem de influência e participação no mercado é limitada, estando as organizações atuando apenas localmente.

Ainda relacionado à produção, percebe-se que a principal matéria-prima utilizada na fabricação é a madeira, em suas mais distintas variações, não descartando, apesar deste fato, a utilização de outros tipos de insumos. Ao mencionar a quantidade de funcionários nas empresas, identifica-se a grande utilização de funcionários próprios e que habitam na cidade, o que consegue explicar a inexistência de funcionários terceirizados. Outros fatores que foram 
analisados são os indicadores pertencentes ao fator estrutural, que indicam como estão as empresas do APL dentro da economia campinense, esses observados no Quadro 4.

Observa-se diante deste Quadro que, apesar de muitas variáveis se apresentarem favoráveis, este fator é considerado desfavorável à competitividade, visto que neste determinante que se refere ao ambiente onde a empresa está inserida, verifica-se que novamente a falta de cooperação entre os envolvidos no setor prejudica intensamente no nível de competitividade.

Quadro 3 - Parâmetros de análise criados para a identificação da competitividade

\begin{tabular}{|c|c|c|c|}
\hline \multicolumn{4}{|c|}{ Determinantes da competitividade - fatores sistêmicos } \\
\hline Dimensão & Variáveis & Avaliação & Percentual \\
\hline Determinantes estruturais & $\begin{array}{l}\text { Características do setor de madeira } \\
\text { e móveis }\end{array}$ & Favorável & Favorável $100 \%$ \\
\hline \multirow{3}{*}{$\begin{array}{l}\text { Determinantes } \\
\text { internacionais }\end{array}$} & Oscilação nas demandas de mercado & Desfavorável & \multirow{3}{*}{$\begin{array}{c}\text { Favorável } \\
33 \% \\
\text { Desfavorável } \\
67 \%\end{array}$} \\
\hline & Flexibilização das estruturas & Favorável & \\
\hline & $\begin{array}{l}\text { Formas de relacionamento entre as } \\
\text { empresas }\end{array}$ & Desfavorável & \\
\hline Determinantes político-institucionais & $\begin{array}{l}\text { Inconstância de políticas de apoio e/ } \\
\text { ou falta de apoio governamental }\end{array}$ & Desfavorável & Desfavorável $100 \%$ \\
\hline Determinantes macroeconômicos & Carga tributária e encargos sociais & Desfavorável & Desfavorável $100 \%$ \\
\hline Resultados: Favorável $33,33 \%$ D & orável $\quad 66,67 \%$ & & \\
\hline
\end{tabular}

Fonte: Dados da pesquisa.

Quadro 4 - Fatores estruturais da competitividade no APL de madeira e móveis

\begin{tabular}{|c|c|c|c|}
\hline \multicolumn{4}{|c|}{ Determinantes da competitividade - fatores estruturais } \\
\hline Dimensão & Variáveis & Avaliação & Percentual \\
\hline \multirow{11}{*}{ Caracterização do APL } & Origem do APL & Favorável & \\
\hline & Tempo de atuação & Favorável & \\
\hline & Origem do capital & Favorável & \\
\hline & Origem do proprietário & Favorável & \\
\hline & & & Favorável \\
\hline & $\begin{array}{l}\text { Funcionário próprios/ } \\
\text { terceirizados }\end{array}$ & Favorável & $80 \%$ \\
\hline & Capacidade produtiva & Desfavorável & $\begin{array}{c}\text { Desfavorável } \\
20 \%\end{array}$ \\
\hline & Linha de produtos & Favorável & \\
\hline & Processo produtivo & Favorável & \\
\hline & Sistemas de produção & Desfavorável & \\
\hline & Formas de produção & Favorável & \\
\hline
\end{tabular}


Quadro 4 - Fatores estruturais da competitividade no APL de madeira e móveis

\begin{tabular}{|c|c|c|c|}
\hline \multicolumn{4}{|c|}{ Determinantes da competitividade - fatores estruturais } \\
\hline Dimensão & Variáveis & Avaliação & Percentual \\
\hline \multirow{7}{*}{ Configuração do APL } & Desempenho e capacitação & Desfavorável & \multirow{7}{*}{$\begin{array}{l}\text { Favorável } \\
28,58 \%\end{array}$} \\
\hline & Empresas correlatas e de apoio & Favorável & \\
\hline & Empresas de comercialização & Desfavorável & \\
\hline & Instituição de apoio & Desfavorável & \\
\hline & Terceirização & Favorável & \\
\hline & Articulação na cadeia produtiva por meio da cooperação & Desfavorável & \\
\hline & $\begin{array}{l}\text { Articulação na cadeia produtiva por meio do fluxo de infor- } \\
\text { mações. }\end{array}$ & Desfavorável & \\
\hline \multirow{7}{*}{$\begin{array}{l}\text { Regime de incentivo e } \\
\text { regulação da concor- } \\
\text { rência }\end{array}$} & Localização & Favorável & \multirow{7}{*}{$\begin{array}{c}\text { Favorável } \\
25 \% \\
\text { Desfavorável } \\
75 \%\end{array}$} \\
\hline & Financiamentos & Favorável & \\
\hline & Informalidade & Desfavorável & \\
\hline & Mão de obra qualificada e de treinamento & Desfavorável & \\
\hline & Incentivos das instituições de apoio, sindicatos e governo & Desfavorável & \\
\hline & $\begin{array}{l}\text { Inexistência de mecanismos de cooperação entre pequenas } \\
\text { empresas }\end{array}$ & Desfavorável & \\
\hline & Falta de atualização tecnológica & Desfavorável & \\
\hline \multirow{4}{*}{ Mercado } & Área de influência & Desfavorável & \multirow{4}{*}{$\begin{array}{c}\text { Favorável } \\
50 \% \\
\text { Desfavorável } \\
50 \%\end{array}$} \\
\hline & Concorrência interna & Favorável & \\
\hline & Valorização do produto local & Favorável & \\
\hline & Acesso a mercados internacionais & Desfavorável & \\
\hline Resultados: Favoráv & Desfavorável $51,72 \%$ & & \\
\hline
\end{tabular}

Fonte: Dados da pesquisa.

Pode-se constatar que a caracterização do APL é a dimensão que melhor favorece a competitividade, pois de todos os indicadores apenas dois se apresentaram desfavoráveis. Para o primeiro, capacidades produtivas, não foram disponibilizados dados para análise, e o sistema de produção apresenta que todas as empresas utilizam o tipo de produção manual, ponto preocupante uma vez que, se acontecer algum imprevisto com um funcionário, a produção é prejudicada, já que este mesmo é o responsável pelo processo produtivo.

Ao se referir à configuração do APL e ao regime de incentivos e regulação da concorrência, percebe-se que uma das principais variáveis é a inexistência da cooperação entre os atores sociais e os atores institucionais, no intuito de melhor desempenhar as atividades no APL. Realizando uma análise à luz dos conceitos de redes interempresariais, pode-se reconhecer a necessidade que as empresas integrantes do APL possuem em criar essa forma de relacionamento, visto que eles são considerados como estratégias e auxiliam no desempenho das mesmas no que tange à competitividade no setor. Criar parcerias com as instituições de apoio é um dos principais pontos a serem adotados para que haja um crescimento favorável à competitividade do setor.

A análise da competitividade em relação aos fatores empresariais apresenta a interação existente 
com os fatores anteriores, com um grau de dependência visível. Como se pode observar no Quadro 5, as práticas organizacionais refletidas pelo ambiente influenciam diretamente na competitividade, uma vez que traz para a empresa características externas a mesma.
Os resultados indicaram que $31,25 \%$ dos fatores competitivos empresariais se apresentam como favoráveis à competitividade, enquanto que $68,75 \%$ como desfavoráveis para o APL campinense de madeira e móveis. Isso pode ser explicado devido à falta de conhecimentos na gestão competitiva empresarial, ou

Quadro 5 - Fatores empresariais da competitividade no APL de madeira e móveis

\begin{tabular}{|c|c|c|c|}
\hline \multicolumn{4}{|c|}{ Determinantes da competitividade - fatores empresariais } \\
\hline Dimensão & Variáveis & Avaliação & Percentual \\
\hline \multirow{4}{*}{ Gestão competitiva } & Planejamento e gerenciamento & Desfavorável & Favorável \\
\hline & Controle financeiro & Desfavorável & $25 \%$ \\
\hline & Estratégia mercadológica & Desfavorável & Desfavorável \\
\hline & Práticas gerenciais cooperativas & Favorável & $75 \%$ \\
\hline \multirow{5}{*}{ Inovação } & Inovação na gestão & Desfavorável & \\
\hline & Inovação no processo & Desfavorável & $\begin{array}{c}\text { Favorável } \\
40 \%\end{array}$ \\
\hline & Inovação no produto & Favorável & \\
\hline & Inovações tecnológicas & Desfavorável & $\begin{array}{c}\text { Desfavorável } \\
60 \%\end{array}$ \\
\hline & Fontes de informação para a inovação & Favorável & \\
\hline \multirow{3}{*}{ Produção } & Atualização do sistema de produção & Desfavorável & Favorável \\
\hline & Desempenho produtivo & Favorável & $\begin{array}{c}33 \% \\
\text { Desfavorável }\end{array}$ \\
\hline & Métodos de produção & Desfavorável & $67 \%$ \\
\hline \multirow{4}{*}{ Recursos humanos } & Qualificação & Desfavorável & \\
\hline & Capacitação e treinamento & Desfavorável & $\begin{array}{c}\text { Favorável } \\
50 \%\end{array}$ \\
\hline & Flexibilidade & Favorável & $\begin{array}{c}\text { Desfavorável } \\
50 \%\end{array}$ \\
\hline & Comprometimento e estímulo à competitividade & Desfavorável & \\
\hline Resultados: Favo & Desfavorável $68,75 \%$ & & \\
\hline
\end{tabular}

Fonte: Dados da pesquisa.

seja, por não haver a realização de uma estratégia mercadológica, bem como práticas gerenciais de cooperação, sendo estes considerados agravantes para a competitividade.

Observa-se, portanto, que não há muito investimento em inovação por parte das empresas. Esta é uma variável que pode ser explicada pelas características inerentes ao arranjo produtivo, como também pelo tradicionalismo apresentado por essas organizações.
Em outro momento, reconhece-se que o bem mais valioso para a empresa é representado por seus colaboradores, pois são responsáveis pelo funcionamento de toda a organização, por isso deve ser um ativo motivado constantemente, a fim de que as metas planejadas pela organização sejam atingidas.

Porém, verifica-se que os colaboradores que formam o APL de madeira e móveis de Campina Grande não estão sendo estimulados para o 
comprometimento e a produtividade, pois há a ausência de uma política de capacitação e treinamento para seus funcionários. Estes são os fatores que diretamente podem afetar a competitividade do APL.

Com base nos resultados referentes aos fatores sistêmicos, estruturais e empresariais da competitividade do Arranjo Produtivo Local de madeira e móveis de Campina Grande, foi possível caracterizá-lo com baixo nível de competitividade, tendo em vista que a média encontrada em relação aos fatores competitivos foi de $62,38 \%$ para os determinantes desfavoráveis e apenas $37,62 \%$ para os favoráveis. Como podemos verificar na Figura 1.

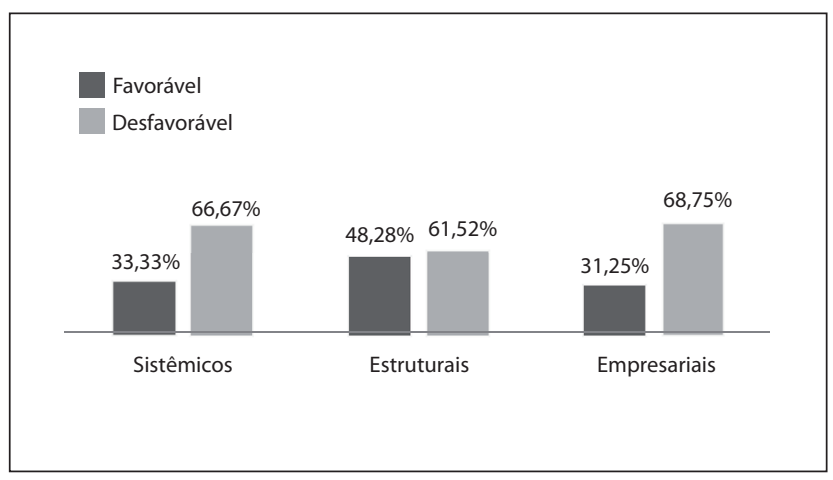

Figura 1 - Performance da competitividade dos fatores sistêmicos, estruturais e empresariais

Fonte: Dados da pesquisa.

A partir da análise da competitividade, foi verificado que possivelmente o APL de madeira e móveis de Campina Grande, PB, não atingiu um nível de amadurecimento para considerar-se como realmente competitivo. Isso pode ser explicado pelo fato de a maioria dos entrevistados pouco conhecer as variáveis que estão envolvidas na competitividade, de forma que isso acaba comprometendo o desenvolvimento de sua empresa diante de um mercado enérgico e competitivo no qual estão inseridos.

\section{Considerações finais}

O ambiente de negócios exige das organizações a formação de interações que consigam direcioná-las a melhores resultados no mercado. Uma das possíveis alternativas estratégicas é formar redes interempresariais que podem ser utilizadas para influenciar no nível de competitividade de um Arranjo Produtivo
Local. A pesquisa apresentou que o APL de madeira e móveis de Campina Grande, $\mathrm{PB}$, se mostra desfavorável à competitividade, visto que ao se analisarem os três fatores que a determinam, o resultado encontrado leva ao entendimento do contexto onde se está envolvido. E exprime que todos esses determinantes podem comprometer a característica competitiva de qualquer aglomerado de empresas.

Verifica-se que as empresas não possuem as capacitações e desempenho adequados que gerem as condições favoráveis para a elaboração de estratégias alinhadas aos padrões de concorrência do atual mercado, o que impede de alcançar resultados satisfatórios para melhorar o desempenho competitivo e o desenvolvimento do APL como um todo.

Percebe-se também que a cooperação é muito baixa, o que prejudica o desempenho do APL. Assim, a falta de incentivos e de interações efetivas com instituições de apoio e governamental é fator determinante que influencia diretamente no desenvolvimento do APL.

Assim sendo, conclui-se que apenas o fato de participar de um APL não necessariamente indica que há competitividade no setor. Portanto, buscar intensificar as relações entre instituições de apoio e com as próprias empresas do APL certamente irá contribuir para ampliar a competitividade dos atores envolvidos.

\section{Referências}

ASSOCIAÇÃO BRASILEIRA DAS INDÚSTRIAS DO MOBILIÁRIO - ABIMÓVEL. Panorama do setor moveleiro no Brasil: informações gerais. São Paulo, 2006.

CÂNDIDO, G. A.; ABREU, A. F. Os conceitos de redes e as relações interorganizacionais: um estudo exploratório. In: ASSOCIAÇÃOS NACIONAL DE PÓS-GRADUAÇÃO E PESQUISA EM ADMINISTRAÇ̃̃O, 24., 2000, Florianópolis. Anais... Florianópolis: EnANPAD, 2000.

CASSIOLATO, J. E.; LASTRES, H. M. M. Relatório de atividades da expansão da RedeSist. Rio de Janeiro: IE/UFRJ, 2004.

COUTINHO, L.; FERRAZ, J. C. Estudo da competitividade da indústria brasileira. São Paulo: Papirus, 1994.

FERRAZ, J. C.; KUPFER, D.; HAGUENAUER, L. Made in Brazil: desafios competitivos para a indústria. Rio de Janeiro: Campus, 1997. 
FEDERAÇÃO DAS INDÚSTRIAS DO ESTADO DA PARAÍBA FIEP. Relação do cadastro das empresas de fabricação de móveis e produtos de madeira. Cadastro Industrial, 2006.

INSTITUTO DE PESQUISA ECONÔMICA APLICADA - IPEA. Identificação, mapeamento e caracterização estrutural de arranjos produtivos locais no Brasil. São Paulo, 2007.

MACÊDO, N. M. M. N.; SILVA, M. E. da; BARROS, R. A. Competitividade agroindustrial: um estudo comparativo a partir de um modelo de competitividade sistêmica. In: ENCONTRO NACIONAL DE ENGENHARIA DE PRODUÇÃO, 30., 2010, São Carlos. Anais... São Carlos: ENEGEP, 2010.

NOLETO, M. J. Parcerias e alianças estratégicas: uma abordagem prática. São Paulo: Global, 2000.
SANTOS, A. R. dos. Metodologia científica: a construção do conhecimento. Rio de Janeiro: DP\&A, 1999.

Recebido: 26/09/2011

Received: 09/26/2011

Aprovado: 18/10/2011

Approved: 10/18/2011 